\title{
RESENHAS RESENHAS RESENHAS RESENHAS
}

https://doi.org/10.1590/198053146408

\section{GÊNERO E DEMOCRACIA: UMA INTRODUÇÃO}

Maira Abreu'

BIROLI, Flavia. Gênero e desigualdades: limites da democracia no Brasil. São Paulo: Boitempo, 2018.

Num contexto de ascensão de forças conservadoras, fortes regressões sociais e ataques aos estudos de gênero e às conquistas do movimento feminista e LGBTTI, o livro de Flávia Biroli chega em boa hora. Ao apresentar de forma clara e didática alguns debates fundamentais do feminismo e dos estudos de gênero, esboçando alguns dos desafios vindouros, a autora contribui para suscitar questionamentos de grande relevância para o momento atual.

O grande mérito da obra é generificar objetos tradicionais da ciência política, isto é, mostrar que eles são atravessados por questões de gênero que, por diferentes razões, entre elas a posição frequentemente privilegiada daqueles/as que produzem conhecimento considerado legítimo, são ocultadas. Criticando o "foco míope" (BIROLI, 2018, p. 54) da política, a autora propõe uma abordagem que supere uma visão abstrata de conceitos como democracia, cidadania, direitos, liberdade, autonomia, indivíduo, que figuram reiteradamente como "neutros" em termos de gênero, mas que, na verdade, são flexionados frequentemente no masculino. Se esses questionamentos já datam de algumas décadas e constituem parte do repertório de base dos estudos de gênero, o mesmo não pode ser dito para a ciência política.

Não é uma particularidade do Brasil o caráter marginal dos estudos de gênero na área de ciência política. França, Estados Unidos e diversos outros países conheceram o mesmo fenômeno. ${ }^{1}$ Como afirma a autora, as teorias feministas da política permitem incorporar a "dimensão da experiência e pôr no centro das discussões a produção cotidiana das desigualdades, da dominação e da resistência” (BIROLI, 2018, p. 212), mas essa perspectiva dificilmente é incorporada pela ciência política de uma forma mais geral e, particularmente, nos debates sobre democracia.

Para Flávia Biroli, além de uma perspectiva que leve em consideração o gênero, é necessário promover uma análise interseccional, embora a autora utilize raramente o termo, preferindo a ideia de "opressões cruzadas" (2018, p. 51), “desigualdades conjugadas de gênero, classe e raça” (p. 66), ou "convergências" entre gênero, raça e classe (p. 72). Essa perspectiva está presente em todo o livro e contribui para trazer à tona a necessidade de tratar gênero, classe e raça de forma

I Universidade de São Paulo (USP), bolsista da Fundação de Amparo à Pesquisa do Estado de São Paulo (Fapesp), São Paulo (SP), Brasil; http://orcid.org/0000-0001-6829-9246; mairabreu@yahoo.com 
articulada, num contexto de crescente interesse no país pelos conceitos de interseccionalidade e/ou consubstancialidade.

Ao sintetizar diversos debates importantes para os estudos de gênero e para o feminismo, tendo como foco o caso brasileiro, a obra supre também uma importante lacuna no país: a inexistência de bons livros introdutórios sobre conceitos e tópicos fundamentais da teoria feminista e do que hoje é chamado de "estudos de gênero" (mas que ganhou diversos nomes ao longo das últimas décadas).

Uma parte da produção desse campo foi muito criticada nas últimas décadas por veicular um discurso abstrato, inacessível e excessivamente distante da prática militante. ${ }^{2}$ Biroli conseguiu produzir um livro acessível, que tem vocação para ir além dos muros das universidades, promovendo debates com movimentos sociais e diferentes atores sociais. No momento atual, de retrocessos nesse campo e da necessidade de pensar articulações políticas, a obra poderá cumprir um importante papel.

O livro é composto por cinco capítulos. No primeiro - Divisão sexual do trabalho -, o objetivo é defender a hipótese de que há uma "conexão da divisão sexual do trabalho com os padrões de participação política” (BIROLI, 2018, p. 23). Para desenvolver o seu argumento, Biroli apresenta de forma panorâmica algumas autoras que tematizaram a divisão sexual do trabalho, como Christine Delphy, Silvia Walby, entre outras. Para o movimento feminista de diversos países, o trabalho doméstico foi um elemento central de teorização e mobilização. Biroli pretende trazer essas reflexões para analisar a democracia.

Para a autora, a divisão sexual do trabalho tem um "impacto profundo nas democracias contemporâneas" (BIROLI, 2018, p. 27), sendo preciso "incorporar uma dimensão estrutural fundamental das relações de gênero - a divisão sexual do trabalho - à análise crítica dos limites da democracia” (p. 52). Numa teoria política "politizada”, “atenta às disputas e às hierarquias que conformam a democracia”, a divisão sexual do trabalho deveria ser um desafio (BIROLI, 2018, p. 43). Mas a dimensão gênero se mostra insuficiente, pois o trabalho doméstico não é vivenciado da mesma forma por mulheres de diferentes classes sociais e raças e, por isso, a autora propõe uma análise que considere todos esses fatores. A baixa presença de mulheres na esfera política não pode ser interpretada somente como fruto dos limites da democracia liberal. O tipo de trabalho remunerado e o tempo despendido com o trabalho doméstico têm um profundo impacto nas possibilidades de participação política (BIROLI, 2018, p. 27). Como a autora afirma na conclusão, "Os muros ou os tetos de vidro que delimitam a participação das mulheres na política são feitos da energia e do tempo que lhes é roubado pelo trabalho prestado aos mais próximos e à sociedade” (BIROLI, 2018, p. 210).

Uma questão que surge a partir da leitura desse capítulo é em relação à escolha das autoras mobilizadas para esse debate. O conceito de divisão sexual do trabalho na França foi teorizado notadamente por autoras que Biroli identifica 
como aquelas que propuseram o conceito de relações sociais de sexo (Danièle Kergoat, Helena Hirata, entre outras). Seriam Delphy, Leonard e Walby as melhores referências para fazer o debate proposto? Considerando que o centro da análise de Delphy é o trabalho doméstico mas não o trabalho remunerado e que uma das críticas que recebeu foi a falta de articulação entre essas duas questões, formulada também como uma falta de articulação entre "produção e reprodução" ou entre "capitalismo e patriarcado", e que essa crítica foi o ponto de partida para algumas autoras que elaboraram o conceito de relações sociais de sexo, a pergunta sobre a escolha das autoras se impõe.

No capítulo 2 - Cuidado e responsabilidades -, é abordado o cuidado, uma questão que estaria "longe de ser um tema com alguma centralidade nos estudos teórico e empíricos sobre a democracia” (BIROLI, 2018, p. 54). Segundo a autora, existe, tal como para a divisão sexual do trabalho, "um paralelo entre as posições de desvantagem nas relações de cuidado e a exclusão ou baixa presença nos ambientes em que leis e políticas são definidas” (BIROLI, 2018, p. 54). Quem e como despende tempo com o cuidado? Qual é a posição em relação ao cuidado daqueles/as que participam da construção teórico-filosófica dos problemas da democracia? De que forma algumas medidas como a PEC 241-55 e mudanças na legislação trabalhista impactam na "crise do cuidado" no país e intensificam as desigualdades de classe, raça e gênero em relação ao acesso ao cuidado? A autora mostra como o não questionamento da divisão sexual do trabalho enquanto base para as políticas de cuidado pode aprofundar desigualdades de gênero. Além disso, a mercantilização do cuidado pode servir a algumas mulheres, mas aprofunda outras desigualdades entre elas. Para a autora, é na convergência entre "convenções de gênero e ampliação da mercantilização das relações" que se produz a desvalorização e precarização do trabalho remunerado doméstico e de cuidado (BIROLI, 2018, p. 82). É preciso buscar outras alternativas que fujam da configuração convencional de gênero e promovam "relações fortalecidas para o provimento de cuidado, relações baseadas em valores solidários, não na lógica do mercado" (BIROLI, 2018, p. 89)

O capítulo 3 - Família e maternidade - fornece um bom panorama das intensas transformações ocorridas ao longo do século XX em relação a essas duas questões. A conquista do direito à capacidade civil plena, em 1962; do divórcio, em 1977; o fim da ideia de autoridade legal do homem sobre a mulher no casamento, com a Constituição de 1988; a separação, ainda que parcial, entre casamento, família e heterossexualidade e a possibilidade de separar sexo e reprodução foram algumas dessas mudanças que ganharam fôlego notadamente a partir dos anos 1960 e, como indica a autora ao longo do livro, foram fruto de intensas mobilizações feministas e disputas políticas. Mostrar como essas transformações foram de grande envergadura, recentes e resultado de lutas é particularmente útil para aquelas/es que hoje, gozando de todos os benefícios dessa nova situação, insistem em deslegitimar o feminismo.

A politização do privado foi uma bandeira central para amplos setores do movimento feminista da segunda onda. Desnaturalizar a ideia de família e 
maternidade foi a base de muitas teorizações feministas. Em relação às teorizações feministas da família, para Biroli (2018, p. 99), essas se concentraram (e continuariam em grande medida a fazê-lo) nas "injustiças intrafamiliares" e na dimensão da família como controle, dando pouca atenção às "desigualdades e as injustiças interfamiliares e a dimensão da família como privilégio”. A autora mobiliza críticas do feminismo negro (Hill Collins, bell hooks, entre outras) para mostrar como o debate sobre família e maternidade não pode ser analisado sem que classe, raça e gênero sejam articulados. Analisá-los a partir do ponto de vista de algumas mulheres pode levar a generalizações abusivas, ocultamentos e aprofundamento de algumas desigualdades. Transformações nas relações de gênero em algumas classes sociais abastadas podem conviver com "profundas desigualdades entre as mulheres" e limites no avanço de uma maior igualdade nas classes populares.

Para Biroli, o "feminismo socialista" teve o mérito de destacar as "desigualdades entre mulheres" e não somente entre homens e mulheres. Assim, Kollontai, ao enfatizar a heterogeneidade do grupo mulheres, teria antecipado alguns debates do feminismo socialista e negro da segunda metade do século XX. Mas é preciso lembrar que, se de fato essas diferenças foram enfatizadas por socialistas e outros setores de esquerda, isso ocorreu muitas vezes para deslegitimar a existência de um movimento feminista, acusado de divisionista. Como afirmava Clara Zetkin (1976, p. 107), "nenhuma agitação especificamente feminista senão agitação socialista entre mulheres. Não devemos pôr em primeiro plano os interesses mais mesquinhos do mundo da mulher: nossa tarefa é a conquista da mulher proletária para a luta de classes".

O direito ao aborto é um elemento central da autonomia das mulheres e foi uma importante bandeira para muitos movimentos feministas da segunda metade do século XX. Para a autora, "falar de aborto é falar, enfim, da democracia e de seus limites" (BIROLI, 2018, p. 147). Analisar essa relação entre aborto e democracia é o objeto do capítulo 4 - Aborto, sexualidade e autonomia. Como as sociedades impedem ou possibilitam o controle das próprias mulheres sobre seus corpos e como as leis e práticas sociais garantem o respeito à integridade física e psíquica dos indivíduos são elementos que precisam ser considerados no debate sobre democracia.

A autora ressalta a importância de abordar a questão incorporando classe e raça. Se nos países de capitalismo avançado a luta pela autonomia do corpo tem como base a escolha da maternidade (o que envolve legalização da contracepção e do aborto), a situação não é a mesma quando se olha para sua periferia. Primeiro, é preciso contextualizar essas escolhas. Quem pode, como e de que forma escolher? Em relação à autonomia, é preciso lembrar que sucessivas políticas de esterilização forçadas são parte da história desses países e atingem as classes populares e determinadas populações racializadas. É por isso que muitas feministas negras, de origem latina e asiática, defendem uma "perspectiva interseccional na definição dos direitos reprodutivos e na agenda de suas lutas” (BIROLI, 2018, p. 144). Um histórico de como a questão da legalização do aborto foi tratada em instâncias como o Congresso Nacional e a influência da Igreja nesses debates são outro elemento analisados que fornecem um panorama dos debates nas últimas décadas. 
Para a autora, embora o diálogo com o movimento feminista tenha se ampliado no governo do Partido dos Trabalhadores, a aliança com setores conservadores impediu que avanços mais substanciais se consolidassem. Mas, se os avanços foram tímidos, eles foram suficientes para suscitar uma grande preocupação e mobilização por parte de setores conservadores. A relação histórica do PT com a Igreja Católica e as alianças desse partido com setores conservadores durante as eleições teriam feito "do PT e de seus governos um fator de fortalecimento dos grupos religiosos da 'religiosização' da política brasileira no Brasil na primeira quadra do século XXI” (BIROLI, 2018, p. 156). Trata-se de uma ideia interessante e que mereceria ser desenvolvida. Seria o PT um dos responsáveis pela "religiosização da política” que contribuiu para sua derrocada?

Os movimentos feministas atuam “fora” e "dentro" do Estado. No capítulo 5 - Feminismos e atuação política -, o objetivo é abordar sobretudo esse último tipo de ação. Apesar de uma presença reduzida das mulheres em cargos eletivos no Brasil (e no mundo de uma forma mais geral), as mulheres, e o movimento feminista, não estiveram ausentes da política institucional. A autora nos faz revisitar a criação e atuação do Conselho Nacional dos Direitos das Mulheres, as diversas ementas apresentadas durante a Constituinte, muitas delas oriundas de grupos feministas, passando por outras ações nos anos 1990 até alcançar o período mais recente. A chegada do Partido dos Trabalhadores ao poder permitiria uma "permeabilidade inédita do Estado" aos movimentos sociais a partir de 2003. Trata-se de um período recente sobre o qual a autora faz uma boa síntese. A criação da Secretaria Especial de Política para Mulheres (2003), a promulgação da Lei Maria da Penha (2006), Lei do feminicídio (2015), a "PEC das domésticas” (regulamentada em junho de 2015) e programas como Brasil sem Homofobia (2004) e Programa Mulher e Ciência (2005) são exemplos de algumas conquistas durante os governos Lula e Dilma. Isso não impediu inflexões conservadoras, como o programa Rede Cegonha, entre outras.

Nesse capítulo são analisadas não apenas as diversas ações no âmbito institucional e as diferentes ementas apresentadas, mas também os limites na construção de uma agenda comum entre mulheres parlamentares. Um paralelo entre essas ações e aquelas do feminismo "fora" do Estado (em alguns casos dos mesmos grupos evocados) poderia fornecer um quadro mais diverso das mobilizações feministas do período, mas isso foge claramente ao escopo desse trabalho. Porém, uma consequência dessa escolha é que se cria um contraste entre esse tipo de ação e o contexto mais recente, no qual haveria uma "multiplicação de coletivos, blogs, revistas e agências de notícias feministas” em que o feminismo ganha novas formas, lutas e organizações (BIROLI, 2018, p. 200). Encontrar a diversidade de formas, lutas e organizações feministas do período anterior implica ir além das ações feministas no Estado.

Ao trazer à tona diversos debates fundamentais, o livro levanta questões interessantes e estimulantes e indica possíveis novos caminhos de pesquisa. Em alguns casos, a própria autora convida a explorar algumas hipóteses e pistas, como em relação à conexão entre divisão sexual do trabalho e democracia, que deveria 
ser “colocada na posição de hipótese para ser testada em pesquisas teóricas e empíricas” (BIROLI, 2018, p. 49). Outros pontos mereceriam também a mesma indicação, como a questão da separação entre teorias gerais e particulares (BIROLI, 2018, p. 25), o "casamento ruidoso e trágico" entre neoliberalismo econômico e conservadorismo moral (p. 211) e a "religiosização da política”. Esses dois últimos ganharam uma grande preeminência no momento das eleições presidenciais de 2018, realizada seis meses após a publicação de Gênero e democracia. O livro serve, assim, como um “convite" ao desenvolvimento dessas questões fundamentais, tanto teórica como politicamente, no contexto atual.

O livro visa claramente a um público pouco familiarizado com o tema. Seu caráter introdutório, particularmente visível nos capítulos 3 , 4 e 5, pode frustrar alguns e particularmente algumas leitoras familiarizadas com os temas. Explicitar melhor esse caráter de introdução e síntese já nas primeiras páginas do livro evitaria que a/o leitor/a criasse falsas expectativas.

Ao promover um diálogo entre temas clássicos da ciência política e as reflexões acumuladas ao longo das últimas décadas pelo movimento feminista e estudos de gênero, esse livro contribui para um olhar menos androcêntrico da política. Ele indica também caminhos para repensar a separação entre teorias "gerais" e "particulares” ou "específicas”. Ultrapassar essa separação é mostrar que o "gênero" não é uma variável, um campo ou uma teoria "específica”, mas sim relações sociais que perpassam a sociedade e cuja invisibilização empobrece nossas pesquisas e tem sérias consequências teóricas e políticas.

\section{REFERÊNCIAS}

BIROLI, Flavia. Gênero e desigualdades: limites da democracia no Brasil. São Paulo: Boitempo, 2018.

HARTMANN, Heidi; BRAVO, Ellen; BUNCH, Charlotte; HARTSOCK, Nancy SPALTER-ROTH, Roberta WILLIAMS, Linda; BLANCO, Maria. Bringing together feminist theory and practice: a collective interview. Signs, v. 21, n. 4, p. 917-951, 1996.

JENSON, Jane; LÉPINARD, Eleonore. Penser le genre en science politique: vers une typologie des usages du concept. Revue Française de Sciences Politique, v. 59, n. 2, p. 183-201, 2009.

RITTER, Gretchen; MELLOW, Nicole. The state of gender studies in political science. Annals of the American Academy of Political and Social Science, n. 571, p. 121-134, 2000.

ZETKIN, Clara. La cuestion feminina y la lucha contra el reformismo. Barcelona: Anagrama, 1976.

\section{COMO CITAR ESTA RESENHA}

ABREU, Maira. Gênero e democracia: uma introdução. Cadernos de Pesquisa, São Paulo, v. 49, n. 172, p. 338-343, abr./jun. 2019. [Seção] Resenhas. Resenha da obra de: BIROLI, Flavia. Gênero e desigualdades: limites da democracia no Brasil. São Paulo: Boitempo, 2018. https://doi.org/10.1590/198053146408 